\title{
Intermittent cold-induced hippocampal oxidative stress is associated with changes in the plasma lipid composition and is modifiable by vitamins $C$ and $E$ in old rats
}

\author{
S. Asha Devi *, K.R. Manjula \\ Laboratory of Gerontology, Department of Zoology, Bangalore University, Bangalore 560 056, India
}

\section{A R T I C L E I N F O}

\section{Article history:}

Received 2 January 2014

Received in revised form 30 April 2014

Accepted 5 May 2014

Available online 13 May 2014

\section{Keywords:}

Hippocampus

Intermittent-cold exposure

Lipid peroxidation

Lipid profile

Vitamin C

Vitamin E

\begin{abstract}
A B S T R A C T
This study primarily investigated the effects of intermittent cold exposure (ICE) on oxidative stress (OS) in the hippocampus $(\mathrm{HC})$ and plasma lipid profile of old male rats. Secondly, it evaluated structural changes in the hippocampus region of the rat's brain. Thirdly, it attempted an evaluation of the effectiveness of the combined supplement of vitamins $\mathrm{C}$ and $\mathrm{E}$ in alleviating cold stress in terms of these biochemical parameters. Thirty male rats aged 24 months were divided into groups of five each: control (CON), cold-exposed at $10{ }^{\circ} \mathrm{C}(\mathrm{C} 10)$, cold-exposed at $5{ }^{\circ} \mathrm{C}(\mathrm{C} 5)$, supplemented control $(\mathrm{CON}+\mathrm{S})$, and supplemented cold-exposed at either $5{ }^{\circ} \mathrm{C}(\mathrm{C} 5+\mathrm{S})$ or $10^{\circ} \mathrm{C}(\mathrm{C} 10+\mathrm{S})$. The rats were on a daily supplement of vitamin $\mathrm{C}$ and vitamin $\mathrm{E}$. Cold exposure lasted $2 \mathrm{~h}$ /day for 4 weeks. Rats showed increased levels of hydrogen peroxide $\left(\mathrm{H}_{2} \mathrm{O}_{2}\right)$, and thiobarbituric acid reactive substances (TBARS) in the $\mathrm{HC}$ at $10^{\circ} \mathrm{C}$ with further increase at $5^{\circ} \mathrm{C}$. Cold also induced neuronal loss in the hippocampus with concomitant elevations in total cholesterol (TCH), triglycerides (TG) and low-density lipoproteins (LDL-C) levels, and a depletion in high-density lipoprotein (HDL-C). A notable feature was the hyperglycaemic effects of ICE and depleted levels of vitamins $\mathrm{C}$ and $\mathrm{E}$ in the hippocampus and plasma while supplementation increased their levels. More importantly, a positive correlation was observed between plasmatic LDL-C, TCH and TG and hippocampal TBARS and $\mathrm{H}_{2} \mathrm{O}_{2}$ levels. Further, intensity of cold emerged as a significant factor impacting the responses to vitamin $\mathrm{C}$ and $\mathrm{E}$ supplementation. These results suggest that cold-induced changes in the plasma lipid profile correlate with OS in the hippocampus, and that vitamin $C$ and $E$ together are effective in protecting from metabolic and possible cognitive consequences in the old under cold exposures.
\end{abstract}

(C) 2014 Elsevier Ltd. All rights reserved.

\section{Introduction}

Brain tissue is vulnerable to oxidative damage since it consumes high levels of oxygen and to lipid peroxidation which is readily peroxidized (Özmen et al., 2007). It is known that, oxidative stress (OS) resulting from exposure to extreme cold can alter neuronal function and this alteration has been associated with neurochemical changes that take place in the different regions of the brain. Incidentally, cold-induced thermoregulation is also associated with increased lipid metabolism and is age-dependent (McDonald et al., 2004). Low temperature exposures lead to an increased metabolic

\footnotetext{
Abbreviations: ICE, intermittent cold exposure; HC, hippocampus; HDL-C, high density lipoprotein cholesterol; LDL-C, low-density lipoprotein cholesterol; LPO, lipid peroxidation; OS, oxidative stress; ROS, reactive oxygen species; TBARS, thiobarbituric acid reactive substances; TCH, total cholesterol; TG, triglycerides.

* Corresponding author. Tel.: +91 802296 1562; fax: +91 8022961020.

E-mail address: asuba@vsnl.com (S. Asha Devi).
}

rate (Selman et al., 2000), elevated reactive oxygen species (ROS) (Venditti et al., 2004) and OS-induced tissue damage (Topp et al., 2000). It is possible that cold-stimulated high metabolic rates can alter blood lipid profiles and accelerate the development and progression of OS-related occupational hazards such as reduced cognitive performance in terms of memory, vigilance and concentration (Pilcher et al., 2002; Palinkas, 2001). In an earlier study, we demonstrated the hypolipidemic effects of vitamin E supplements with age in rats (Asha Devi et al., 2003a). Incidentally, LPO and cholesterol metabolism have been related to a number of OS-related diseases in the older brain.

Animal studies have shown that the structure and function of hippocampus (HC), a brain region that is important for cognition is adversely affected by conditions such as obesity and hyperlipidemia (Morisson et al., 2010; Farr et al., 2008). Further, the mechanisms that are responsible for hyperlipidemia impacting the $\mathrm{HC}$ may be related to situations that cause increased LPO and OS under situations such as intermittent cold exposures (ICE). 
Vitamin $\mathrm{E}$ ( $\alpha$-tocopherol) is the most important antioxidant that is distributed in the lipid phase of the cells and can react directly with the free radicals, including hydrogen peroxide $\left(\mathrm{H}_{2} \mathrm{O}_{2}\right)$ and superoxide $\left(\mathrm{O}_{2}^{--}\right)$produced by oxidative stress, and can interrupt lipid peroxidation (LPO) by scavenging the peroxidation intermediates (Asha Devi and Ravi, 2004). Studies indicate that vitamin E has a critical role in maintaining metabolic integrity of neurons and has been shown to reduce degeneration of hippocampal neurons following oxidative stress (Crouzin et al., 2010). $\alpha$-Tocopherol along with vitamin C (ascorbic acid), a water-soluble vitamin is likely to exert a synergistic action since vitamin $\mathrm{E}$ is reduced to a tocopheroxyl radical and subsequently reduced back to $\alpha$-tocopherol by ascorbic acid. The synergistic effect of the two vitamins is seen in tissues of rats that are subjected to oxidative stress situations such as cold exposure (Asha Devi et al., 2012) and diabetes with age (Naziroğlu et al., 2011). Animals experience neuronal injury in the $\mathrm{HC}$ as a consequence of exposure to intermittent cold stress since structural changes are noticed in the $\mathrm{HC}$ with regard to stress (Sapolsky, 2000). However, the effectiveness of a combined supplement of vitamin $\mathrm{C}$ and $\mathrm{E}$ on the hippocampal responses and its correlation with plasma lipid profile under cold exposures has not been evaluated in the old subjects.

In the present study we evaluated whether there is a correlation between the plasma lipid changes and hippocampal oxidative stress parameters in the old rats that were intermittently exposed to cold temperatures. Since exposure to cold is known to raise the metabolic rate the degree of response might vary at the two temperatures. Further, a difference of $5{ }^{\circ} \mathrm{C}$ could be more stressful with the progression of age due to weakened thermoregulatory capacity. In this study, TBARS, a LPO product and hydrogen peroxide $\left(\mathrm{H}_{2} \mathrm{O}_{2}\right)$ levels indicative of cellular metabolism were checked for ICE-induced OS in the $\mathrm{HC}$ along with the probable neuronal loss under ICE. Further, the study examined whether a combined supplement of vitamin $C$ and $E$ would have a protective effect on oxidative stress in the hippocampus and plasma lipid profile as well.

\section{Materials and methods}

All fine chemicals and $\alpha$-tocopherol were obtained from SigmaAldrich (St. Louis, MO). Ascorbic acid was procured from Spectrochem (Mumbai). All other chemicals were of analytical grade and solvents were of spectral grade.

\subsection{Animal maintenance and experimental design}

All animal procedures were approved by the Institutional Animal Ethics Committee (IAEC), Bangalore University, Bangalore.

Thirty young (1-month-old) male albino Wistar rats of equal body mass were procured from the Central Animal Facility, IISc, Bangalore, and maintained until they were 24 months of age. They were housed at $24 \pm 2{ }^{\circ} \mathrm{C}$, relative humidity of $70 \pm 1 \%$, and had free access to food (Amruth Feeds, India) and water. After acclimation for 4 weeks in our animal facility, they were assigned to six groups of five animals each: animals at housing room temperature (RT, $\left.25^{\circ} \mathrm{C}, \mathrm{CON}\right)$, animals exposed to $10^{\circ} \mathrm{C}(\mathrm{C} 10)$, animals exposed to $5^{\circ} \mathrm{C}(\mathrm{C} 5)$, animals supplemented $(\mathrm{CON}+\mathrm{S})$ and exposed to $10^{\circ} \mathrm{C}$ $(\mathrm{C} 10+\mathrm{S})$ and $5^{\circ} \mathrm{C}(\mathrm{C} 5+\mathrm{S})$. The supplement was a daily oral gavage of $400 \mathrm{mg}$ vitamin $\mathrm{C}$ and $50 \mathrm{IU}$ of vitamin $\mathrm{E} / \mathrm{kg}$ body weight using a microsyringe. The purpose of including the $\mathrm{CON}+\mathrm{S}$ sub-group in all of our studies was to determine whether combined supplementation has an antioxidant effect and to emphasize their influence, if any, under cold-induced oxidative injury. Food consumption and body weights were measured on a daily and weekly basis respectively.

\subsection{Cold exposure schedule}

During the light phase of the L:D cycle, rats of the ICE stress groups were transported in their home cages, with food, water and bedding into a temperature-controlled chamber and exposed to either $5^{\circ} \mathrm{C}$ or $10^{\circ} \mathrm{C}$ for $2 \mathrm{~h}$ before being returned to their housing facility. The procedure was repeated every day for 4 consecutive weeks. Rats in the control condition remained in the housing facility during this period. Temperatures and periods of cold exposure were selected as per the literature (Şahin and Gümüşlü, 2004) and based on our earlier studies (Manjula et al., 2013) on whole body exposure and in vitro studies on noxious cold exposures of sensory neurons from rat dorsal root ganglion (Naziroğlu and Özgül, 2012).

\subsection{Tissue preparation}

Immediately following the last exposure, animals were mildly etherized and the brain was quickly removed from the calvarium by opening the lateral sides of the skull. The brain was dissected on ice-cold surface and the hippocampus was isolated approximately between bregma $-1.20 \mathrm{~mm}$ and $-5.28 \mathrm{~mm}$ using the anterior commissure as the reference point (Glowenski and Iversen, 1966). A 5\% homogenate was prepared in ice-cold $50 \mathrm{mM}$ phosphate buffer ( $\mathrm{pH} 7.0$ ) containing $0.1 \mathrm{mM}$ EDTA using an ice-chilled Potter homogenizer with a teflon pestle. $100 \mu \mathrm{l}$ of diluted homogenate was used for TBARS assay.

\subsection{Biochemical estimations}

\subsubsection{Blood glucose}

Glucose was measured by the method of Nelson (1944). In brief, blood was deproteinised by adding a mixture of barium hydroxide and zinc sulphate and was then filtered. The filtrate was treated with alkaline copper sulphate solution and boiled for $20 \mathrm{~min}$. This was followed by the addition of arsenomolybdate and diluted to an appropriate volume and the color developed was measured at $540 \mathrm{~nm}$ in a spectrophotometer (ELICO, SL 159, India).

\subsubsection{Plasma}

$2 \mathrm{ml}$ of blood was drawn into EDTA-coated tubes and centrifuged at $600 \times \mathrm{g}$ for $10 \mathrm{~min}$ at $4{ }^{\circ} \mathrm{C}$. The separated plasma was used for measuring the lipid profile.

2.4.2.1. Measurement of plasma lipid profile. Total cholesterol (TCH), high density lipoprotein (HDL-C), triglycerides (TG), and low density lipoproteins (LDL-C) were measured using cogent kits from Span Diagnostics Ltd., India. LDL-C was calculated using Friedewald's method (1972).

\subsubsection{Hippocampus}

2.4.3.1. Vitamin $E$ and $C$. Vitamin $\mathrm{E}$ in the $\mathrm{HC}$ was measured by the method of Desai (1984) and as described in detail earlier (Asha Devi et al., 2003b). In brief, $\mathrm{HC}$ was homogenised in isotonic $\mathrm{KCl}$ and the extraction of vitamin E from HC was performed on TLC plates by the modified method of Kayden and Traber (1993). Standard $\alpha$-tocopherol was spotted and the plates were run using 2:1 benzene-ethyl acetate as solvent system. Reference plates were sprayed with $0.001 \%$ rhodamine $6 \mathrm{G}$ in purified methanol to identify $\alpha$-tocopherol. The silica gel corresponding to the reference plates was eluted in purified ethanol and centrifuged at $600 \times g$ for $5 \mathrm{~min}$ and $0.2 \%$ bathophenanthroline reagent, $0.001 \%$ ferric chloride and orthophosphoric acid were added to the extract. The absorbency of samples and the standard were obtained at $536 \mathrm{~nm}$. Tissue and plasma vitamin E were expressed in terms of $\mu \mathrm{g} / \mathrm{g}$ tissue and $\mu \mathrm{g} / \mathrm{ml}$ plasma. 
Vitamin C was determined by the method of Omaye et al. (1979) by the oxidation of ascorbic acid to dehydroascorbic acid which reacts with 2,4,-dinitrophenyl hydrazine to form 2,4-dinitrophenyl hydrazone. Absorption was read at $520 \mathrm{~nm}$ and vitamin $\mathrm{C}$ was expressed as $\mu \mathrm{g} / \mathrm{g}$ tissue and $\mu \mathrm{g} / \mathrm{ml}$ plasma.

2.4.3.2. Thiobarbituric acid reactive substances (TBARS). The generation of TBARS of which malondialdehyde (MDA) is a product of LPO was measured spectrophotometrically (ELICO, SL 159, India) by the method of Ohkawa et al. (1979). TBARS was expressed in terms of nmol MDA/mg protein, using a standard curve prepared from measurements with a standard solution, 1,1,3,3-tetramethoxypropane.

2.4.3.3. Hydrogen peroxide assay. The procedure used was a modified version of Bruce and Winge (1984) as explained elsewhere (Jolitha et al., 2009). The rate of $\mathrm{H}_{2} \mathrm{O}_{2}$ released by the mitochondria was measured fluorimetrically (Genway, Model 6299, UK), following the method of Hyslop and Skar (1984) by the oxidation of p-hydroxyphenylacetate, coupled to the enzymatic reduction of $\mathrm{H}_{2} \mathrm{O}_{2}$ by horseradish peroxidase. $\mathrm{H}_{2} \mathrm{O}_{2}$ release rate was expressed in terms of $\mathrm{nmol} / \mathrm{mg}$ protein $/ \mathrm{min}$.

2.4.3.4. Protein measurement. Protein concentration in the HC was estimated by the method of Lowry et al. (1951) using bovine serum albumin (BSA) as standard.

\subsection{Histological examination}

Isolated hippocampus was fixed in a neutral $10 \%$ formalin solution. After hydration procedures, the tissue specimens were embedded in paraffin wax and $5 \mu \mathrm{m}$ thickness sections were obtained and stained with hematoxylin and eosin. CA1, CA3 and dentate gyrus (DG) sites in the hippocampus were identified with the aid of stereotaxic atlas (Paxinos and Watson, 2004). Measurements were obtained from 3 images per rat. The number of pyknotic neurons in the sections was counted using light microscopy (Olympus IX, Japan) under a 40-fold magnification objective. Three sections were taken from each animal and the average number of pyknotic neurons in a fixed field was counted. The acidophilic neurons were identified by very intense cytoplasmic eosinophilia along with nuclear membrane disruption and were estimated on a $0-3$ grading scale wherein $0=$ none, $<10 \%=0.5$ (slight), $26-45 \%=1.0$ (mild), $46-54 \%=2$ (moderate), $55-75 \%=2.5$ (moderate-to-severe) and $>75 \%=3$ (severe), as previously reported by Fujikawa et al. (2000). Histological evaluations were performed in a blind manner.

\subsection{Statistical analyses}

The mean and standard error of the mean (SEM) values were calculated for the five animals in each subgroup. The data were subjected to two-way analysis of variance (ANOVA) and Bonferroni post hoc test to compare intergroup significance by using
GraphPad prism software package. Pearson's correlation coefficient was used to determine the relationship between plasma lipid profile and the extent of changes in the variables in the hippocampus. Probability values $p<0.05$ were considered significant.

\section{Results}

Food intake and body mass patterns of rats when exposed to ICE are shown in the Supplementary table (Table S1). Cold-exposed rats gained weight compared to controls. Increases in feeding efficiency were evident $(F=303.8, p<0.0001)$ in the cold-exposed and supplemented rats.

\subsection{Blood glucose}

The Supplementary figure (Fig. S) shows the glucose levels in the cold stressed animals at $5{ }^{\circ} \mathrm{C}$ and $10{ }^{\circ} \mathrm{C}$. Glucose increased significantly $(F=5.12, p<0.005)$ in the cold-exposed, the extent of increase being higher at $5{ }^{\circ} \mathrm{C}$ than at $10{ }^{\circ} \mathrm{C}$. However, supplementation resulted in the glucose levels returning to the control level.

\subsection{Plasma lipid profile}

The mean levels of plasma TCH, TG and LDL-C were significantly $(F=5.147, p<0.005)$ increased in the cold-exposed compared to the controls and the extent of increase was higher at $5{ }^{\circ} \mathrm{C}$ than at $10^{\circ} \mathrm{C}$. Supplementation, however, resulted in decreases $(p<0.005)$ compared to unsupplemented levels. Unlike the above parameters, HDL-C reduced significantly $(p<0.005)$ in rats exposed at $10^{\circ} \mathrm{C}$ and $5{ }^{\circ} \mathrm{C}$ as well as in relation to their controls. Supplementation increased HDL-C $(p<0.005)$ and the extent was higher at $5{ }^{\circ} \mathrm{C}$ than at $10^{\circ} \mathrm{C}$ (Table 1 ).

The changes in the ratios of lipid profile are shown in Table 2. The magnitude of decrease in the LDL-C/HDL-C, TC/HDL-C and TG/HDL-C ratios in the supplemented cold-exposed samples was greater at $5^{\circ} \mathrm{C}$ than at $10^{\circ} \mathrm{C}(F=58.79, p<0.0001)$.

\subsection{Hippocampus}

\subsubsection{Vitamins $C$ and $E$}

The mean values of tissue vitamin $C$ and $E$ in the cold exposed are shown in Table 3. Vitamins $C(F=54.6, p<0.0001)$ and $E$ $(F=79.03, p<0.0001)$ decreased significantly at $10^{\circ} \mathrm{C}$ with a further decrease at $5{ }^{\circ} \mathrm{C}$ with regard to their controls. Supplementation, however, increased the levels of the two vitamins.

The Supplementary table (Table S2) represents the plasma vitamin $C$ and $E$ levels in the cold stressed and control rats. Cold exposure resulted in significantly $(p<0.0001)$ decreased levels of plasma vitamins, and the decrease was directly proportional to the degree of severity of cold exposure. On the contrary, supplementation with vitamin $\mathrm{E}$ and $\mathrm{C}$ to the cold-exposed samples resulted in significantly increased levels of antioxidants.

Table 1

Influence of vitamin C and vitamin E supplementation on the lipid profile following cold exposure in old rats.

\begin{tabular}{|c|c|c|c|c|c|c|}
\hline \multirow[t]{2}{*}{ Plasma } & \multicolumn{6}{|l|}{ Groups } \\
\hline & CON & $\mathrm{CON}+\mathrm{S}$ & $\mathrm{C} 10$ & $\mathrm{C} 10+\mathrm{S}$ & C5 & $\mathrm{C} 5+\mathrm{S}$ \\
\hline $\mathrm{TCH}(\mathrm{mg} / \mathrm{dl})$ & $158.4 \pm 0.9^{\mathrm{a}}$ & $153.5 \pm 3.9^{\mathrm{a}}$ & $182 \pm 4.0^{\mathrm{b}}$ & $155 \pm 1.4^{\mathrm{a}}$ & $198.1 \pm 4.6^{\mathrm{c}}$ & $154 \pm 1.0^{\mathrm{a}}$ \\
\hline HDL-C (mg/dl) & $27.9 \pm 0.2^{\mathrm{a}}$ & $29.8 \pm 0.7^{\mathrm{a}}$ & $19.6 \pm 0.6^{\mathrm{b}}$ & $27.9 \pm 0.7^{\mathrm{a}}$ & $18.3 \pm 1.1^{\mathrm{b}}$ & $27.6 \pm 0.4^{\mathrm{a}}$ \\
\hline TG (mg/dl) & $106 \pm 1.5^{\mathrm{a}}$ & $90.6 \pm 0.9^{\mathrm{b}}$ & $125 \pm 1.6^{\mathrm{c}}$ & $97.4 \pm 3.2^{\mathrm{ab}}$ & $130 \pm 2.0^{c}$ & $107 \pm 2.1^{\mathrm{ab}}$ \\
\hline LDL-C (mg/dl) & $109.3 \pm 0.9^{a}$ & $107 \pm 4.5^{\mathrm{a}}$ & $137 \pm 4.2^{\mathrm{b}}$ & $108 \pm 2.1^{\mathrm{a}}$ & $153 \pm 5.8^{\mathrm{b}}$ & $104 \pm 0.7^{\mathrm{a}}$ \\
\hline
\end{tabular}

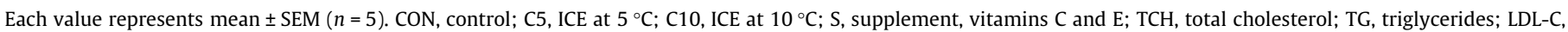

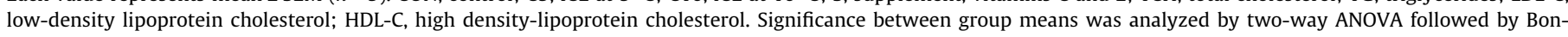

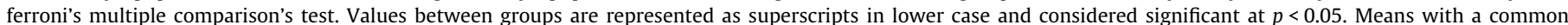
superscript are not significantly different $(p>0.05)$. 
Table 2

Influence of vitamin C and vitamin E supplementation on the mutual ratios of plasma lipid parameters following cold exposure in old rats.

\begin{tabular}{|c|c|c|c|c|c|c|}
\hline \multirow[t]{2}{*}{ Ratio } & \multicolumn{6}{|l|}{ Groups } \\
\hline & CON & $\mathrm{CON}+\mathrm{S}$ & $\mathrm{C} 10$ & $\mathrm{C} 10+\mathrm{S}$ & C5 & $\mathrm{C} 5+\mathrm{S}$ \\
\hline TCH/HDL-C & $5.67 \pm 0.05^{\mathrm{a}}$ & $5.16 \pm 0.10^{\mathrm{a}}$ & $9.32 \pm 0.16^{c}$ & $5.56 \pm 0.15^{\mathrm{a}}$ & $10.9 \pm 0.87^{b}$ & $5.57 \pm 0.03^{\mathrm{a}}$ \\
\hline TG/HDL-C & $3.79 \pm 0.05^{\mathrm{a}}$ & $3.04 \pm 0.02^{\mathrm{b}}$ & $6.42 \pm 0.11^{\mathrm{d}}$ & $3.48 \pm 0.02^{\mathrm{a}}$ & $7.16 \pm 0.34^{\mathrm{c}}$ & $3.90 \pm 0.07^{a}$ \\
\hline LDL-C/HDL-C & $3.91 \pm 0.04^{\mathrm{a}}$ & $3.55 \pm 0.10^{\mathrm{a}}$ & $7.04 \pm 0.14^{\mathrm{c}}$ & $3.86 \pm 0.15^{\mathrm{a}}$ & $8.52 \pm 0.81^{\mathrm{b}}$ & $3.79 \pm 0.25^{\mathrm{a}}$ \\
\hline LDL-C/TG & $1.08 \pm 0.02^{\mathrm{a}}$ & $1.16 \pm 0.02^{\mathrm{a}}$ & $1.30 \pm 0.02^{\mathrm{b}}$ & $1.10 \pm 0.05^{\mathrm{a}}$ & $1.39 \pm 0.01^{\mathrm{b}}$ & $0.97 \pm 0.00^{\mathrm{a}}$ \\
\hline
\end{tabular}

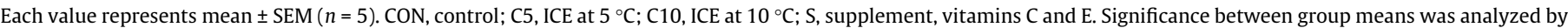

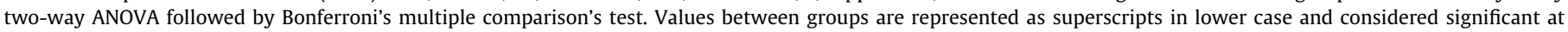
$p<0.05$. Means with a common superscript are not significantly different $(p>0.05)$.

Table 3

Influence of vitamin C and vitamin E supplementation on the concentration of vitamins in the hippocampus following cold exposure.

\begin{tabular}{|c|c|c|c|c|c|c|}
\hline \multirow[t]{2}{*}{ Vitamin } & \multicolumn{6}{|l|}{ Groups } \\
\hline & CON & $\mathrm{CON}+\mathrm{S}$ & $\mathrm{C} 10$ & $\mathrm{C} 10+\mathrm{S}$ & C5 & $\mathrm{C} 5+\mathrm{S}$ \\
\hline Vit. E $(\mu \mathrm{g} / \mathrm{g})$ & $18.96 \pm 1.2^{\mathrm{a}}$ & $38.42 \pm 2.4^{\mathrm{b}}$ & $16.55 \pm 1.5^{\mathrm{a}}$ & $30.85 \pm 1.9^{\mathrm{b}}$ & $13.80 \pm 1.0^{\mathrm{a}}$ & $31.77 \pm 2.7^{b}$ \\
\hline Vit. C ( $\mu \mathrm{g} / \mathrm{g})$ & $234.0 \pm 10.0^{\mathrm{a}}$ & $451.6 \pm 18.1^{\mathrm{b}}$ & $181.1 \pm 12^{\mathrm{ac}}$ & $299.0 \pm 7.4^{\mathrm{ad}}$ & $142.6 \pm 13.0^{c}$ & $274.8 \pm 12^{\mathrm{ad}}$ \\
\hline
\end{tabular}

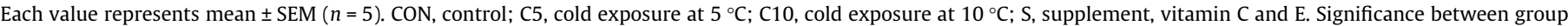

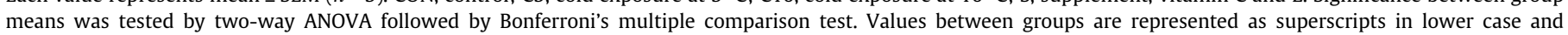
considered significant at $p<0.05$. Means with a common superscript are not significantly different $(p>0.05)$.

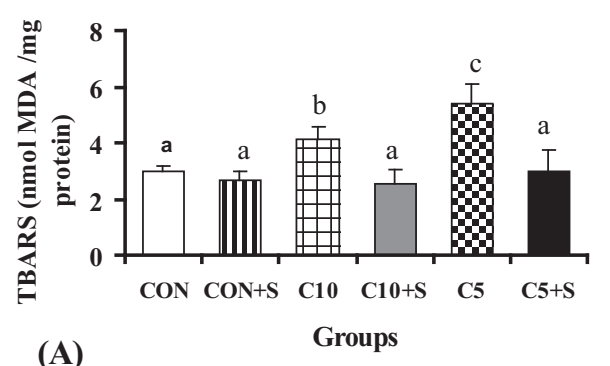

(A)

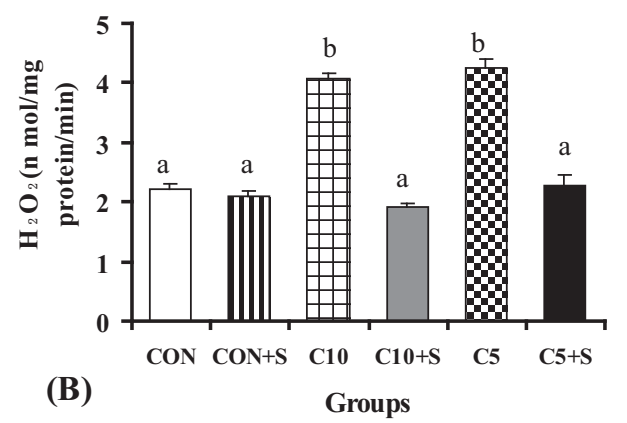

Fig. 1. Effects of intermittent cold exposure on the TBARS (A) and $\mathrm{H}_{2} \mathrm{O}_{2}$ (B) levels in the hippocampus of old rats. Each value represents mean $\pm \operatorname{SEM}(n=5)$. CON, control; C5, ICE at $5{ }^{\circ} \mathrm{C}$; $\mathrm{C} 10$, ICE at $10^{\circ} \mathrm{C}$; S, supplement, vitamins $\mathrm{C}$ and $\mathrm{E}$. Significance between group means was analyzed by two-way ANOVA followed by Bonferroni's multiple comparison's test. Means with a different letter are different from the others $(p<0.05)$ and with a common letter are not significantly different $(p>0.05)$.

\subsubsection{Lipid peroxidation level (TBARS)}

The levels of TBARS are shown in Fig. 1A. There was significant increase $(F=58.79, p<0.0001)$ compared to the controls in the levels of TBARS in the hippocampus of cold-exposed rats while the supplementation reduced these levels. However, the magnitude of these changes was more at $5^{\circ} \mathrm{C}$ than at $10^{\circ} \mathrm{C}$.

\subsubsection{Hydrogen peroxide level $\left(\mathrm{H}_{2} \mathrm{O}_{2}\right)$}

The changes in the $\mathrm{H}_{2} \mathrm{O}_{2}$ generation under cold exposures are shown in Fig. $1 \mathrm{~B} . \mathrm{H}_{2} \mathrm{O}_{2}$ levels were higher in the cold-exposed than
Table 4

Pearson correlation coefficient assessed between parameters measured in all experimental groups in hippocampus of aging rats.

\begin{tabular}{lllllll}
\hline & $\mathrm{H}_{2} \mathrm{O}_{2}$ & TBARS & TC & HDL-C & TG & LDL-C \\
\hline $\mathrm{G}$ & 0.23 & 0.32 & 0.24 & -0.30 & 0.34 & 0.34 \\
$\mathrm{H}_{2} \mathrm{O}_{2}$ & & $0.95^{* *}$ & $0.97^{* *}$ & $-0.98^{* *}$ & $0.94^{* *}$ & $0.97^{* *}$ \\
TBARS & & & $0.99^{* *}$ & $-0.95^{* *}$ & $0.93^{* *}$ & $0.98^{* *}$ \\
$\mathrm{TC}$ & & & & $-0.97^{* *}$ & $0.92^{* *}$ & $0.99^{* *}$ \\
$\mathrm{HDL}-\mathrm{C}$ & & & & & $-0.96^{* *}$ & $-0.97^{* *}$ \\
TG & & & & & & $0.91^{*}$
\end{tabular}

Data are presented as ' $r$ ' values. $(n=5)$.

* Correlation is significant at 0.05 level (2-tailed).

** Correlation is significant at 0.01 level (2-tailed).G, group; $\mathrm{H}_{2} \mathrm{O}_{2}$, hydrogen peroxide; TBARS, thiobarbituric acid reactive substances; TCH, total cholesterol; TG, triglycerides; LDL-C low-density lipoprotein cholesterol; HDL-C, high densitylipoprotein cholesterol.

in controls. $\mathrm{H}_{2} \mathrm{O}_{2}$ was significantly elevated above the control level $(F=102.7, p<0.0001)$. Supplementation induced a modulatory effect by significantly reducing the $\mathrm{H}_{2} \mathrm{O}_{2}$ values compared to the unsupplemented.

3.3.3.1. Correlation between measured plasmatic lipid parameters. TCH showed a moderate negative correlation with HDL $(-0.57, p<0.01)$ and a positive correlation with TG $(+0.82$, $p<0.01)$ and LDL $(+0.97, p<0.01)$. TG showed a positive correlation with LDL $(+0.82, p<0.01)$ (Table 4$)$.

3.3.3.2. Plasmatic lipid profile versus lipid peroxidation in the hippocampus. A positive correlation was observed with TBARS in the HC and plasma TCH $(r=+0.88 ; p<0.01)$, LDL-C $(+0.83, p<0.01)$, and TG $(+0.84 ; p<0.01)$ with a moderate negative correlation with HDL-C $(-0.52, p<0.01)$ (Table 4$)$.

3.3.3.3. Histology. Examples of $\mathrm{H} \&$-E staining in the hippocampus of controls and cold-exposed rats are shown in Fig. 2. Compared to controls, cold exposure at $10{ }^{\circ} \mathrm{C}$ increased the number of damaged neurons (Fig. 2B) and was more in the dentate gyrus compared to the CA1 and CA3 regions (Table 5). Supplementation was not effective in reducing the damaged neurons in the cold-exposed rats. Compared to $10^{\circ} \mathrm{C}$, rats at $5{ }^{\circ} \mathrm{C}$ showed more of damaged neurons. Supplementation, however, significantly reduced $(p<0.05)$ the 

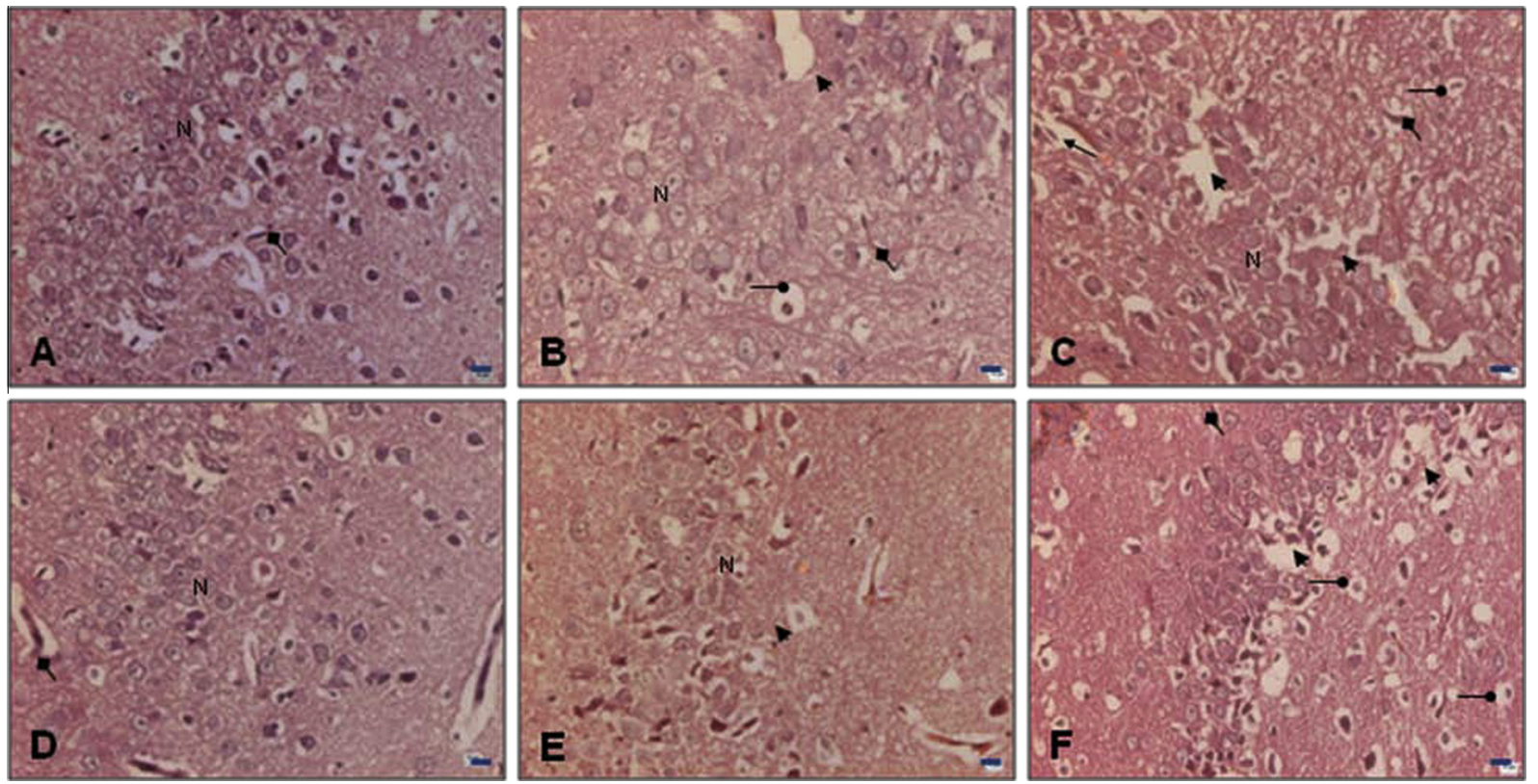

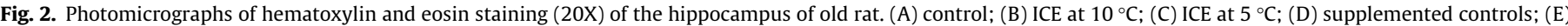

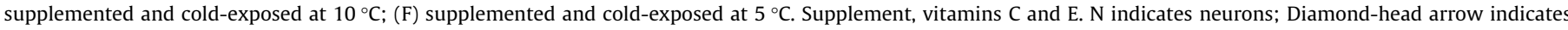
blood vessels; arrow indicates perivascular space; arrow head indicates interstitial spaces; oval-head arrows show dark neurons. Scale $=10 \mu \mathrm{m}$.

Table 5

Morphological examination for damaged neurons in the hippocampus of experimental groups of old rats.

\begin{tabular}{|c|c|c|c|c|c|c|}
\hline \multirow[t]{2}{*}{ Group } & \multicolumn{2}{|l|}{ DG } & \multicolumn{2}{|l|}{ CA1 } & \multicolumn{2}{|l|}{ CA3 } \\
\hline & $\%$ & G & $\%$ & G & $\%$ & G \\
\hline CON & $40.7 \pm 0.9^{\mathrm{a}}$ & 1.5 & $36.2 \pm 2.7^{\mathrm{a}}$ & 1.5 & $29.2 \pm 1.6^{\mathrm{a}}$ & 1.5 \\
\hline $\mathrm{CON}+\mathrm{S}$ & $32.1 \pm 0.7^{b}$ & 1.5 & $29.7 \pm 1.6^{\mathrm{b}}$ & 1.5 & $22.3 \pm 1.6^{\mathrm{b}}$ & 1.0 \\
\hline $\mathrm{C} 10$ & $53.5 \pm 1.5^{c}$ & 2.0 & $47.2 \pm 1.5^{c}$ & 2.0 & $40.5 \pm 0.7^{c}$ & 1.5 \\
\hline $\mathrm{C} 10+\mathrm{S}$ & $52.4 \pm 6.4^{\mathrm{c}}$ & 2.0 & $45.9 \pm 5.2^{c}$ & 2.0 & $36.2 \pm 1.5^{c}$ & 1.5 \\
\hline $\mathrm{C} 5$ & $63.2 \pm 2.7^{\mathrm{d}}$ & 2.5 & $58.3 \pm 6.4^{\mathrm{d}}$ & 2.5 & $49.5 \pm 2.7^{\mathrm{d}}$ & 2.0 \\
\hline $\mathrm{C} 5+\mathrm{S}$ & $55.5 \pm 7.6^{\mathrm{c}}$ & 2.5 & $48.5 \pm 5.2^{\mathrm{c}}$ & 2.0 & $37.7 \pm 0.9^{c}$ & 1.5 \\
\hline
\end{tabular}

Each value represents mean \pm SEM $(n=5)$. CON, control; $\mathrm{C} 5$, cold exposure at $5^{\circ} \mathrm{C}$; $\mathrm{C} 10$, cold exposure at $10^{\circ} \mathrm{C} ; \mathrm{S}$, supplement, vitamin $\mathrm{C}$ and $\mathrm{E} ; \mathrm{G}$, gradation of injury; $1.0=$ mild $(10-25 \%) ; 1.5=$ mild-to-moderate $(26-45 \%) ; 2.0=$ moderate $(46-54 \%) ;$ DG, dentate gyrus, CA1, cornus ammonis 1; CA3, cornus ammonis 3. Significance between groups means was tested by two-way ANOVA followed by Bonferroni's multiple comparison test. Values between groups are represented as superscripts in lower case and considered significant at $p<0.05$. Means with a common superscript are not significantly different $(p>0.05)$.

number with respect to the unsupplemented rats. The damaged neurons were assessed by increased numbers of acidophilic neurons as identified by very intense cytoplasmic eosinophilia (Fig. 2C) while those on combined supplement showed fewer number of such neurons (Fig. 2E and F).

\section{Discussion}

Our data on feeding behaviour show that increased food consumption in cold stressed animals is not surprising since enhanced food intake is linked to the energy expenditure necessary for heat production. The principal findings of the present study are threefold.

The first relates ICE induced hyperglycaemic condition in the old rats (Fig. S). The hyperglycemic effect of cold stress is similar to that reported by Larkin et al. (1992) in 26-mo-old male rats that were cold-stressed at $5^{\circ} \mathrm{C}$ for $4 \mathrm{~h}$. The hyperglycaemic effect may be related to the diminished ability to oxidise carbohydrates in the cold and the mechanisms can be attributed to the increased plasma glucose levels in cold-stressed rats due to increased plasma glucagon leading to elevated hepatic gluconeogenesis and ketogenesis (Seitz et al., 1981) and this may not be the case in the old rats since the uptake and metabolism of glucose is reduced with age.

Further, the observed hyperglycaemia in the cold stressed rats was accompanied by elevated LDL-C levels suggesting that increased glucose may lead to LDL-C oxidation since glycated LDL is a preferred compound for oxidative modifications (Sobal et al., 2000). The present results on increased LDL-C/TG and LDL-C/ HDL-C ratios in animals exposed to cold are indicative of LDL oxidation in vivo with the former ratio being suggested as an important predictor of LDL oxidation (Brizzi et al., 2005). Although we have not measured the TCH in the hippocampus, studies by Cutler et al. (2004) have documented increased TCH in old mice at 25 months of age, and have related the increase to similar situations of oxidative stress involving activation of sphingomyelinases resulting in ceramide production and accumulation of TCH, and have shown that $\alpha$-tocopherol is effective in inhibiting the enzymes. A decrease in HDL in response to cold exposure can be explained by the fact that in rats HDL is the main fraction transporting cholesterol. Additionally, HDL cholesterol regulates the exchange of proteins and lipid between lipoproteins, and thereby inhibits the oxidation of LDL due to its antioxidative property (Das, 2003).

Second, the reduced temperatures showed an increased LPO with a concomitant increase in the $\mathrm{H}_{2} \mathrm{O}_{2}$ level in the $\mathrm{HC}$; these changes were dependent on the intensity of the cold. The magnitude of the changes in the TBARS level was proportional to the intensity of the cold. Cold stress possibly increases the production of ROS such as hydrogen peroxide $\left(\mathrm{H}_{2} \mathrm{O}_{2}\right)$, hydroxyl radicals ( $\mathrm{HO}$ ) and superoxide anion radicals $\left(\mathrm{O}_{2}^{-\cdot}\right)$ which in turn causes peroxidation of lipids. The results on increased LPO under cold stress in the rats are consistent with other reports on peripheral tissues (Şahin and Gümüşlü, 2004; Venditti et al., 2004). The increased neuronal damage seen in our study in rats subjected to cold-stress is because of excess $\mathrm{H}_{2} \mathrm{O}_{2}$ generation in the hippocampus. This is substantiated by earlier studies (Aihara et al., 2001) who have shown that 
several ion channels with high thermal sensitivity result in molecular complexity, suggesting that their differential expression in particular neurons in the hippocampus may influence their response to low temperatures and by Naziroğlu and Özgül (2011) who used $\mathrm{H}_{2} \mathrm{O}_{2}$ in an experimental model of oxidative stress.

Third, the results of this study also revealed that supplementation with vitamins $\mathrm{C}$ and $\mathrm{E}$ under ICE not only lowered the LDL-C/ HDL-C and TCH/HDL-C ratios but also lowered $\mathrm{H}_{2} \mathrm{O}_{2}$ generation in the HC. Vitamin $\mathrm{C}$ and $\mathrm{E}$ are antioxidants that prevent LDL oxidation by retarding the generation of ROS (Shariat et al., 2013; Sakuma et al., 2001). The significantly reduced ascorbic acid levels in the HC under ICE, in spite of the rat hepatocyte's ability to synthesise ascorbic acid de novo from glucose explains the increased requirement of the vitamin to overcome excess OS. Low concentration of ascorbic acid in rats subjected to ICE explains a plausible interaction of vitamin $C$ with membrane-bound vitamin $E$ reducing the tocopherol radical back to tocopherol. Vitamin $\mathrm{E}$ reduction under ICE is known to promote LPO making the cells more susceptible to oxidative injury (Fukui et al., 2001).

The results showing an inverse relation between TBARS and, depletions in vitamin $\mathrm{C}$ and $\mathrm{E}$ levels in the HC of the cold-stressed rats may explain the increased predisposition for generation of TBARS under stress. It appears that the increased level of $\mathrm{H}_{2} \mathrm{O}_{2}$ can increase the generation of lipid peroxides and cause greater damage to the neurons. Substantial protection is reported by Gracy (2007) in the hippocampal neurons when treated with $\alpha$-tocopherol prior to and during $\mathrm{H}_{2} \mathrm{O}_{2}$ exposure to the oxidative stress. In the present study, the results on reduced levels of vitamin $\mathrm{E}$ in the $\mathrm{HC}$ of the cold-exposed rats are in accordance with the reports on increased TBARS levels in the brains of cold-stressed animals with a reversal of the depleted levels of vitamin $E$ in treated animals (Celikbilekal et al., 2014). Apart from vitamin E, vitamin $C$ has the ability to protect against LPO by scavenging the ROS, and by a one-electron reduction of lipid hydroperoxyl radicals via the vitamin $\mathrm{E}$ redox cycle. We have previously reported that vitamin $C$ with vitamin E significantly lowers OS in the hypothalamus of cold-exposed male rats belonging to different age groups (Manjula et al., 2013).

Our findings on higher LPO at $5{ }^{\circ} \mathrm{C}$ than at $10{ }^{\circ} \mathrm{C}$ indicate that the acute cold stress that the animal undergoes at lower temperature suggests an increased oxygen consumption, oxidative metabolism, elevated ROS production and heat production. The two temperatures may also suggest step-wise alterations in energy generation and subsequent alterations in the concentration of ROS as the response of organisms to low temperatures depend on the duration of exposure and the intensity of coldness (Blagojević, 2007).

Finally, in the HC, LPO correlated positively with an increase in plasmatic TCH, TG and LDL-C and negatively with HDL-C. Combined treatment with vitamins $\mathrm{C}$ and $\mathrm{E}$ in the present study attenuated hyperglycemia and lowered oxidative stress in the hippocampus of old rats.

Our findings on ICE-induced hypercholesterolemia and altered lipid profile may be corroborated by the high incidence of metabolic disorders such as hypertension and atherosclerosis in cold-exposed workers. Since exposure of the whole body to ICE is a metabolic stressor and under natural situations ICE is encountered sporadically more often than continuous, old workers who are intermittently exposed to cold areas may be protected from the metabolic and cognitive loss due to OS via supplementation with vitamins $\mathrm{C}$ and $\mathrm{E}$.

\section{Acknowledgements}

This work was supported by the University Grants Commission, New Delhi (Referral No.F.No. 33-356/2007) to Dr. S. Asha Devi. The financial assistance to Dr. S. Asha Devi under the Promotion of
University Research and Scientific Excellence (PURSE)-Department of Science and Technology (DST), New Delhi (No. SR/S9/Z023/2010/ 38 ) is also gratefully acknowledged.

\section{Appendix A. Supplementary data}

Supplementary data associated with this article can be found, in the online version, at http://dx.doi.org/10.1016/j.neuint.2014. 05.001 .

\section{References}

Aihara, H., Okada, Y., Tamaki, N., 2001. The effects of cooling and rewarming on neuronal activity of pyrimidal neurons in guinea pig hippocampal slices. Brain Res. 893, 36-45.

Asha Devi, S., Ravi, K.T., 2004. Regional responses in antioxidant system to exercise training and dietary vitamin E in aging rat brain. Neurobiol. Aging 25, 501-508.

Asha Devi, S., Prathima, S., Subramanyam, M.V.V., 2003a. Dietary vitamin E and physical exercise: I. Altered endurance capacity and plasma lipid profile in ageing rats. Exp. Gerontol. 38, 285-290.

Asha Devi, S., Prathima, S., Subramanyam, M.V.V., 2003b. Dietary vitamin E and physical exercise: antioxidant status and lipofuscin-like substances in ageing rat heart. Exp. Gerontol. 38, 291-297.

Asha Devi, S., Manjula, K.R., Subramanyam, M.V.V., 2012. Protective role of vitamins $\mathrm{E}$ and $\mathrm{C}$ against oxidative stress caused by intermittent cold exposure in aging rat's frontoparietal cortex. Neurosci. Lett. 529, 155-160.

Blagojević, D.P., 2007. Antioxidant systems in supporting environmental and programmed adaptations to low temperatures. Cryo Lett. 28, 137-150.

Brizzi, P., Tonolo, G., Carusillo, F., Malaguarnera, M., Maioloi, M., Musumeci, S., 2005. Plasma lipid composition and LDL oxidation. Clin. Chem. Lab. Med. 41, 56-60.

Bruce, G.L., Winge, D.R., 1984. Subcellular distribution of superoxide dismutase in rat liver. Methods Enzymol. 105, 105-108.

Celikbilekal, A., Gocmena, A.Y., Tanikal, N., Yarasa, N., Yargicoglua, P., Gumuslua, S., 2014. Serum lipid peroxidation markers are correlated with those in brain samples in different stress models. Acta Neuropsychiatrica 26, 51-57.

Crouzin, N., Ferreira, M., Cohen-solal, C., Barbanel, G., Guiramand, J., Vignes, M., 2010. Neuroprotection induced by vitamin $\mathrm{E}$ against oxidative stress in hippocampal neurons: involvement of TRPV1 channels. Mol. Nutr. Food Res. 54, 496-505.

Cutler, R.G., Kelly, J., Stone, K., Pedersen, W.A., Tammara, A., Hatanpaa, K., Troncoso, J.C. Mattson, M.P., 2004. Involvement of oxidative stress-induced abnormalities in ceramide and cholesterol metabolism in brain aging and Alzheimer's disease. Proc. Natl. Acad. Sci. USA 101, 2070-2075.

Das, D.K., 2003. Cardioprotection with high density lipoprotein, Fact or fiction? Circ. Res. 92, 258-260.

Desai, I.D., 1984. Vitamin E analysis methods for animal tissues. Methods Enzymol. $105,138-147$.

Farr, S.A., Kelvin, A. Yamada, D., Butterfield, A. Abdul, H.A., Xu, L., Miller, N.E., Banks, W.A., Morley, J.E., 2008. Obesity and hypertriglyceridemia produce cognitive impairment. Endocrinology 149, 2628-2636.

Friedewald, D.G., Levy, R.J., Fredrickson, D.S., 1972. Estimation of the concentration of low density lipoprotein cholesterol in plasma, without use of the preparative ultracentrifuge. Clin. Chem. 18, 499-502.

Fujikawa, D.W., Shinmei, S.S., Cai, B., 2000. Kainic acid-induced seizures produce necrotic, not apoptotic neurons with internucleosomal DNA cleavage: implications for programmed cell death mechanisms. Neuroscience 98, 41-53.

Fukui, K., Onodera, K., Shinkai, T., Suizuki, S., Urano, S., 2001. Impairment of learning and memory in rats caused by oxidative stress and aging, and changes in antioxidative defense systems. Ann. NY Acad. Sci. 928, 168-175.

Glowenski, J., Iversen, L.L., 1966. Regional studies of catecholamines in the rat brain: the deposition of $\left[{ }^{3} \mathrm{H}\right]$ norepinephrine, $\left[{ }^{3} \mathrm{H}\right]$ dopamione and $\left[{ }^{3} \mathrm{H}\right]$ DOPA in various regions of the brain. J. Neurochem. 13, 655-699.

Gracy, R.W., 2007. Effects of vitamin E on the apoptotic cascade; studies in neuronal cells. In: Preedy, V.R., Watson, R.R. (Eds.), Encyclopedia of Vitamin E. CABI Publishing, Cambridge, MA, pp. 480-486.

Hyslop, P.A., Skar, L.A., 1984. Quantitative fluorimetric assay for the determination of oxidant production by polymorph nuclear leukocytes: its use in simultaneous fluorimetric assay of cellular activation processes. Anal. Biochem. 141, 280-286.

Jolitha, A.B., Subramanyam, M.V.V., Asha Devi, S., 2009. Age-related responses of the rat cerebral cortex: influence of vitamin $\mathrm{E}$ and exercise on the cholinergic system. Biogerontology 10, 53-63.

Kayden, H.J., Traber, M.G., 1993. Absorption, lipoprotein transport and regulation of plasma concentrations of vitamin E in humans. J. Lipid Res. 34, 343-358.

Larkin, L.M., Horwitz, B.A., McDonald, R.B., 1992. Effect of cold on serum substrate and glycogen concentration in young and old Fischer 344 rats. Exp. Gerontol. 27, $179-190$.

Lowry, O.H., Rosenberg, N.J., Farr, A.L., Randall, R.J., 1951. Protein measurements with the Folin-Phenol reagent. J. Biol. Chem. 193, 265-275.

Manjula, K.R., Subramanyam, M.V.V., Asha Devi, S., 2013. Protection against oxidative stress caused by intermittent cold exposure by combined supplementation with vitamin $\mathrm{E}$ and $\mathrm{C}$ in the aging rat hypothalamus. Neurochem. Res. 38, 876-885. 
McDonald, R.B., Gabaldón, A.M., Horwitz, B.A., 2004. Aging ad thermoregulation. In: Kuchel, G.A., Lof, P.R. (Eds.), Autonomic Nervous System. Karger, Basel, pp. 120 133.

Morisson, C.D., Pistell, P.J., Ingram, D.K., Johnson, W.D., Liu, Y., Fernandez-Kim, S.O., White, C.L., Puirpera, M.N., Uranga, R.M., Bruce-Keller, A.J., Keller, J.N., 2010. High fat diet increases hippocampal oxidative stress and cognitive impairment in aged mice: implications for Nrf2 signaling. J. Neurochem. 114, 1581-1589.

Naziroğlu, M., Özgül, C., 2011. Vitamin E modulates oxidative stress and protein kinase $\mathrm{C}$ activator (PMA)-induced TRPM2 channel gate in dorsal root ganglion of rats. J. Bioenergy Biomembr. 45, 541-549.

Naziroğlu, M., Özgül, C., 2012. Effects of antagonists and heat on TRPM8 channel currents in dorsal root ganglion neuron activated by nociceptive cold stress and menthol. Neurochem. Res. 37, 314-320.

Naziroğlu, M., Butterworth, P.J., Sonmez, T.T., 2011. Dietary vitamin C and E modulates antioxidant levels in blood, brain, liver, muscle and testes in diabetic aged rats. Int. J. Vitam. Nutr. Res. 81, 347-357.

Nelson, 1944. Determination of blood glucose. J. Biol. Chem. 153, 375-380.

Ohkawa, H., Ohishi, N., Yagi, K., 1979. Assay for lipid peroxidation in animal tissues by thiobarbituric acid reaction. Anal. Biochem. 95, 351-358.

Omaye, S.T., Turnbull, J.D., Sauberlich, H.E., 1979. Selected methods for the determination of ascorbic acid in animal cells, tissues and fluids. Methods Enzymol. 62, 3-11.

Özmen, I., Naziroğlu, M., Alici, H.S., Sahin, F., Cengiz, M., Eren, I., 2007. Spinal morphine administration reduces the fatty acid contents in spinal cord and brain in rabbits due to oxidative stress. Neurochem. Res. 32, 19-25.

Palinkas, L.A., 2001. Mental and cognitive performance in the cold. Int. J. Circumpolar Health 60, 430-439.

Paxinos, G., Watson, C., 2004. The Rat Brain in Stereotaxic Coordinates, fifth ed. Academic Press, New York.
Pilcher, J.J., Nadler, E., Busch, C., 2002. Effects of hot and cold temperature exposure on performance: a meta-analytic review. Ergonomics 45, 682-698.

Şahin, E., Gümüşlü, S., 2004. Cold-stress-induced modulation of antioxidant defence: role of stressed conditions on tissue injury followed by protein oxidation and lipid peroxidation. Int. J. Biometeorol. 48, 165-171.

Sakuma, N., Yoshikawa, M., Hibino, A., Sato, A., Kamiya, Y., Ohte, N., Tamai, N. Kijnimatsu, M., Kimura, G., Inoue, M., 2001. Ascorbic acid protects against peroxidative modification of low-density lipoprotein maintaining its recognition by LDL receptors. J. Nutr. Sci. Vitaminol. 47, 28-31.

Sapolsky, R.M., 2000. The possibility of neurotoxicity in the hippocampus in major depression; a primer on neuronal death. Biol. Psychiatry 48, 755-765.

Seitz, H.J., Krone, W., Wilke, H., Tarnowski, W., Carsten, D., Dunkelmann, B., Harneit, A., 1981. Rapid rise in plasma glucagons induced by acute cold exposure in man and rat. Pflügers Arch. 389, 115-120.

Selman, C., McLaren, J.S., Himanka, M.J., Speakman, J.R., 2000. Effect of long-term cold exposure on antioxidant enzyme activities in a small mammal. Free Radic. Biol. Med. 28, 1279-1285.

Shariat, S.Z.A.S., Mostafavi, S.A., Khakpour, F., 2013. Antioxidant effects of vitamins E and $\mathrm{C}$ on the low-density lipoprotein oxidation mediated by myeloperoxidase. Iran Biomed. J. 17, 22-28.

Sobal, G., Menzel, J., Sinzinger, H., 2000. Why is glycated LDL more sensitive to oxidation than native LDL? A comparative study. Prostaglandins Leukot. Essent. Fatty Acids 63, 177-186.

Topp, H., Lengger, C., Schoch, G., Werner, J., Mietzsch, E., 2000. Renal excretion of 8 oxo-7,8-dihydro-2' deoxyguanosine in Wistar rats with increased $\mathrm{O}(2)$ consumption due to cold stress. Arch. Biochem. Biophys. 376, 328-332.

Venditti, P., De Rosa, R., Portero-otin, M., Pamplona, R., Di Meo, S., 2004. Coldinduced hyperthyroidism produces oxidative damage in rat tissues and increases susceptibility to oxidants. Int. J. Biochem. Cell Biol. 36, 1319-1331. 